\title{
Consideraciones para el diseño de apps para bebés
}

Design Considerations in Apps for Babies

Miriam Morante

Nuria Rodríguez

María Costa

Palabras clave: Aplicaciones, bebés, diseño, juego tecnología, pantallas Key words: Apps, babies, design, play, technology, screens.
En los últimos años ha habido una explosión de aplicaciones (Apps) enfocadas al público infantil. A pesar de ser un target muy vulnerable, no existe documentación específica para que los desarrolladores creen Apps apropiadas para bebés. Ante tal necesidad, llevamos a cabo una investigación desde el punto de vista de la pedagogía, la psicología infantil y el diseño, para crear una guía con recomendaciones para el desarrollo de Aplicaciones para bebés. Las recomendaciones de diseño abarcan una amplia gama de información, desde formatos $y$ estéticas una amplia gama de información, desde formatos y estéticas adecuadas a cada etapa evolutiva, hasta el contenido lúdico, educativo e interactivo apropiado para los pequeños.

In recent years there has been an explosion of applications targeted at children, even babies. Despite being a very vulnerable target, there is no specific documentation for developers to create Apps appropriate for babies. For this reason, we conducted an investigation from the point of view of pedagogy child psychology and design, to crete a guide with recommendation for the deve and design, to create a guide with recommendations for the developmen of applications for babies. The recommendations for designing Apps for babies cover a wide range of information from formats and aesthetics to appropriate recreational, educational and interactive content related to each stage of the baby's development.
1. Introducción

Los datos muestran que el acceso a los dispositivos móviles está aumentando rápidamente entre familias'. Los adultos usan constantemente aplicaciones en varios dispositivos para diferentes áreas de sus vidas, y cuando se convierten en padres siguen utilizándolas. Nuestro estudio muestra que una cantidad muy elevada de los padres en España están fascinados por la tecnología y la innovación y son muy receptivos a jugar con ellas con sus hijos, incluso cuando son bebés. Los dispositivos móviles son una interfaz con la que interactúan día a día con sus hijos para temas relacionados con su salud, su seguridad, su aprendizaje y su entretenimiento ${ }^{2}$

Existe gran controversia ante el uso de estas nuevas tecnologías con niños. Mientras diversas asociaciones de pediatría recomiendan evitar totalmente su uso con niños muy pequeños, otros expertos indican que el "determinismo tecnológico", es decir, pensar que una forma de tecnología es en general dañina, es una idea demasiado simplista. A falta de estudios, aún no podemos concluir si su impacto en bebés es positivo o negativo y en qué aspectos puede serlo.

Nuestra investigación parte de la idea de que una App puede ser beneficiosa o perjudicial dependiendo en gran medida del diseño, la propuesta de juego y el uso que se haga de ella. No obstante, por el momento no existen teorías unificadas sobre las características pedagógicas, lúdicas y de diseño que han de tener las Apps para dirigirse a bebés. Por ello, muchas de las aplicaciones existentes se basan en los principios de diseño de contenidos y productos tradicionales. Esto da lugar a versiones de Apps con enfoques que no tienen en cuenta las peculiaridades únicas de juego que se pueden potenciar a través de tecnologías móviles. En muchas ocasiones se traslada directamente a las pantallas de dispositivos móviles lo que se ha diseñado para pantallas grandes o para otros soportes. Los desarrolladores necesitan entender lo que es diferencial en los dispositivos móviles para diseñar aplicaciones que aprovechen sus atributos particulares $^{3}$. Es necesario empezar a elaborar teorías y modelos específicos que permitan guiar en el desarrollo de Apps para niños pequeños aprovechando la potencialidad de la unicidad de los dispositivos y de público al que se dirigen.

El objetivo general de nuestro estudio ha sido promover y ampliar la investigación científica centrada en el uso y desarrollo de aplicacio-
1 RIDEOUT, V. (2013). Zero to Eight: Children's media use in Ame rica. Common Sense Media. 2 COSTA, M; BUSO, P.; MOTendencias en Puericultura 2014 Tendencias en Puericultura 2014Infancia. 3 SHULER, C. (2009) Pockets of potential. Using mobile technologies to promote children's learning The Joan Ganz Cooney Center at Sesame Workshop. nes para las familias con bebés. Además de perseguir ampliar y crear documentación específica para universidades, centros de formación desarrolladores y la industria para mejorar el diseño de aplicaciones para niños menores de 24 meses.

Por ello hemos llevado a cabo un análisis de las propiedades y características que deben tener las Aplicaciones móviles para bebés, investigación que ha generado una serie de recomendaciones. Algunos de los puntos más relevantes se presentan en el presente artículo. 


\section{Metodología}

Para desarrollar la presente investigación se ha analizado el comportamiento de los niños menores de dos años en su juego con Apps. Teniendo en consideración los datos obtenidos, se ha aplicado y traducido al diseño de aplicaciones móviles la información disponible sobre estéticas, formatos, orientación y distribución de elementos adecuados para el desarrollo de juegos digitales infantiles.

Los datos se apoyan en una primera fase de la investigación, llevada a cabo en 2014, en la que se realizó un estudio con 110 padres españoles con niños de 0 a 2 años, tras el que se analizaron las características de las 44 Apps que estaban siendo usadas por las familias.

Concretamente, la metodología utilizada para determinar las capacidades de los bebés en el uso de Apps y dispositivos móviles ha sido la siguiente:

- Estudio observacional: observación en profundidad de 33 casos de bebés en diferentes estadios evolutivos, mientras usaban Apps. Análisis de vídeos hechos por padres en el entorno natura del niño.

- Estudio longitudinal: seguimiento de un caso desde el nacimiento hasta los 24 meses. Análisis de los cambios en sus capacidades y patrones de juego con dispositivos móviles.

\section{Consideraciones para el diseño interactivo}

Lo primero que se ha de tener en cuenta para desarrollar Apps es entender quién es el usuario y cómo las puede usar. Es imprescindible plantearse lo más especificamente possible la edad a la que irá dirigida la aplicación. Un niño de tres meses es totalmente distinto a un niño de doce meses y estas diferencias son fundamentales a la hora de generar Apps que se adecuen a las posibilidades físicas y cognitivas del pequeño. Cuanto más adecuada sea la App a la edad del niño, mejores posibilidades tendrá ésta de atraer a bebés y adultos, y menos efectos negativos podrá tener en el desarrollo del pequeño. Nuestra investigación ha aportado datos específicos por edades para poder tener un mejor conocimiento de las principales formas y posibilidades de los bebés de interactuar con dispositivos móviles.

3.1. El bebé y la evolución de sus capacidades de interacción con Apps

Durante los primeros meses de vida, los padres son los protagonistas absolutos del mecanismo de aprendizaje, modulando las actividades. Son ellos quienes preparan las aplicaciones, colocan y sostienen el soporte móvil y al bebé de una forma específica. En esta etapa ellos son quienes realmente manejan las aplicaciones, pero también existe una interacción bebé-dispositivo puesto que éstos reciben algún tipo de estímulo que puede generar en ellos una respuesta.

En el primer mes o dos de vida, el niño no intenta tocar el dispositivo. Permanece en el lugar donde se le ha dejado, simplemente estando. Puede escuchar y visualizar pasivamente lo que sucede en el dispositivo. Aunque realmente no se fija en la pantalla, ni centra la vista en ella más de unos pocos segundos.

Alrededor del tercer mes, en brazos de sus padres, puede tener interés en alcanzar y tocar la pantalla, pero sin ningún control ni precisión en sus movimientos. Toca por azar en cualquier zona de la pantalla con toda la mano abierta o con el puño. Aún tardará varios meses en controlar los movimientos de sus manos. Solo se centra brevemente en lo que hay en la pantalla, se distrae y mira otras cosas con facilidad. Puede que se ponga el dispositivo en la boca. Con las tabletas, al tener mayor superficie, tienen más posibilidad de tocar algo por azar que con los teléfonos inteligentes.

Hacia el sexto mes el pequeño arrastra con los dedos la pantalla de un lado a otro cambiando la "página", pero sin ningún control real sobre lo que está haciendo. Parece interesado en la mecánica de cambiar la imagen de la pantalla con el movimiento de sus manos pero no se fija en el contenido a no ser que un adulto tome el control y se pare a explicarle.

Hacia el séptimo mes aún toca la pantalla con todos los dedos, la golpea. Pero ya coge bien el dispositivo. Le interesa y lo analiza girándolo y mirándolo detenidamente desde varias perspectivas (sobretodo los smartphones). Puede golpearlo o tirarlo bruscamente.

Entre el décimo mes y el primer año de vida empieza a poder imitar y reproducir mejor algunas acciones que ve o que se le muestran. Por ejemplo, desbloquear la pantalla. En esta fase y en los próximos meses disfruta apretando botones. Si la App tiene un botón de Home, le da constantemente. Ya puede prestar más atención a lo que se muestra en la pantalla durante un periodo mayor de tiempo. Coge el dispositivo con una mano y toca la pantalla con la otra, lo que puede ser problemático cuando la mano que coge el dispositivo evita que funcione el App.

A partir del año, muestra confusión entre lo que puede hacer con las pantallas y la vida real: toca los libros como si pudiera pasar las páginas arrastrando los dedos, le da a una imagen con el dedo esperando que pase algo, etc. Puede tocar la pantalla con un dedo o con toda la mano. Ya no da a la pantalla sólo por azar, toca donde sabe que pasará algo, o hace la acción de pasar páginas con intención. Le interesa manipular, salir y entrar de Apps, mover la pantalla, etc. Sigue cambiando constantemente de App. Encuentra nuevas formas de usar los dispositivos que ni siquiera los padres conocían. También experimenta tocar la pantalla con los pies y otros utensilios.

Hacia los quince o dieciséis meses coge el dedo del adulto y lo guía hasta donde quiere que éste haga lo que él no ha conseguido hacer. Sabe que hay un botón de encender y apagar. Entiende que hay que subir y bajar el volumen para que funcione. Y muestra preferencia e interés por el dispositivo móvil frente a otros juguetes.

Más allá de los dieciocho meses el pequeño sabe cuando la App ha de ir en vertical u horizontal. Muchas veces sigue entrando y saliendo de una App a otra, pero, gracias a su evolución cognitiva empieza a 
prestar atención durante más tiempo a una App específica. Puede arrastrar formas y llevarlas a un lugar concreto si el recorrido es corto y sencillo. Cerca de los dos años ya sabe como manejarse bien en el entorno gráfico; como entrar y salir de las Apps, dónde buscarlas, etc. No obstante, muestra confusión cuando maneja libros y otros juguetes.

Por ejemplo, espera obtener resultados al arrastrar o tocar una imagen con el dedo. Es de gran relevancia para el niño en esta fase que pueda experimentar cómo funcionan los juguetes y productos físicos antes de jugar con los digitales. Previamente a jugar con puzles-app debería manejar bien los puzles reales. Es una etapa en la que se intensifican las rabietas si se le quita el dispositivo. Los padres tienen que poder darle al niño otras opciones que les entretengan igualmente y para ello han de haber podido tener una gran variedad de experiencias con otras tipologías de juego y actividades.

Estos datos generales ayudan a entender mejor las habilidades de los niños frente a las pantallas móviles, pero es importante recalcar que las posibilidades manipulativas de un niño con Apps dependen de diversos factores por lo que puede variar ampliamente, sobretodo en niños tan pequeños. Uno de esos factores es el contacto previo que haya tenido cada pequeño con Apps. No es lo mismo un bebé de 9 meses que nunca ha tocado un móvil anteriormente, que el que ha estado algunos meses ya experimentando sus posibilidades.

\subsection{Acciones concretas que los niños pueden realizar}

Para diseñar correctamente un juego digital para bebés, y en general para cualquier público objetivo, es necesario entender las acciones que van a poder realizar. Estas consideraciones ayudan a que el pequeño pueda divertirse y evitar la frustración ante la imposibilidad de hacer algo. Exponemos seguidamente algunas de las acciones que se pueden implementar en el diseño de Apps para menores de dos años, y aquellas que se deberían evitar.

3.2.1. Acciones que los niños podrían realizar.

Tap/ golpear. Es la forma más intuitiva y natural para el niño de interactuar con la pantalla y por lo tanto es la acción en la que deberían basarse la mayoría de juegos cuyo target sean bebés.

Multi-touch. Los niños ponen múltiples dedos a la vez en la pantalla involuntariamente y con limitada destreza, lo que no ha de resultar un problema sino que se ha de tener en consideración como parte del juego. Es más recomendable que los juegos no requieran de respuestas correctas (como un toque en el lugar correcto), sino que se basen en procesos de acción-reacción simplemente con tocar la pantalla de cualquier forma, sin mucha precisión.

Mover el dedo o la mano por la pantalla. Una acción simple que requerirá de una reacción sonora o visual. Se ha de tener en cuenta que a veces no levantan los dedos, por lo que la acción debería estar programada para empezar cuando tocan no cuando levantan el dedo.

A partir de los 12-18 meses, dependiendo de la experiencia previa que haya tenido el niño con Apps podrá también arrastrar una imagen de un sitio a otro, aunque no suelen entender donde se ha de soltar el objeto hasta que tienen al menos cerca de 2 años. Se ha de considerar que suelen tener dificultad en mantener el dedo tocando una imagen con la continuidad necesaria para arrastrarla el tiempo requerido. Por lo tanto el recorrido debería ser sencillo, cercano y directo y sin mucha exactitud. Por ejemplo, permitir arrastrar hacia los bordes de la pantalla siendo este el objetivo del juego.

La interacción planteada para los bebés más pequeños no debería requerir mucha exactitud. Las Aplicaciones no han de ser muy sensibles al lugar donde toca para que pase una acción concreta. El área estipulada para que el niño toque y se genere una acción ha de ser amplia y los elementos interactivos han de estar bien separados entre sí. Todo ello con el objetivo de dar bastante margen de error y evitar la frustración. La destreza requerida no debe ser muy grande y el resultado debe producirle una satisfacción inmediata, para que el niño vea que su acción vale la pena. Cuando el bebé vaya creciendo se puede restringir más el área, por ejemplo cambiando el nivel de dificultad. Lo que puede resultar interesante para fomentar su motricidad fina.

Es importante que las acciones que se generen obtengan un feedback inmediato, para que el niño entienda bien que ha pasado algo debido a su acción. Los pequeños tienden a darle a la pantalla demasiado fuerte, demasiado tiempo, demasiadas veces seguidas muchas veces hasta que ven que su acción ha sido registrada. Por lo que se ha de programar la App de forma que se genere una respuesta visual y sonora al tocar y no al levantar el dedo 4 .

Una acción que en principio no requiere de mucha exactitud es la de cambiar páginas. A los niños pequeños, según nuestras observaciones, les interesa y atrae la mecánica de pasar páginas, que se convierte en sí para ellos en acción lúdica. Por lo tanto, se pueden generar opciones de juegos que se basen simplemente en permitir el movimiento de cambiar de izquierda a derecha o viceversa las imágenes que aparecen en pantalla. También en cada pantalla o página se puede añadir algún tipo de acción lúdica adicional pero de características simples.

Un problema detectado en el juego es cuando se permiten hacer varias acciones en la misma pantalla. Por ejemplo, si hay un personaje al que se le ha de tocar para que reaccione, es mejor que no tenga en la misma pantalla otras posibilidades como repetir lo que se le dice. Las funciones han de estar separadas para que el niño se centre en una acción lúdica que se le plantea, evitando así generar confusiones.

Por otro lado, es importante que el juego no requiera de scrolling o desplazamiento vertical para poder acceder a contenidos que hay por debajo de los que se ve en la pantalla. Esta acción es conceptualmente difícil para los niños. El desplazamiento horizontal es más intuitivo.

La tecnología actual permite además de interactuar con las imáge-

4 SesameWorkshop (2012) Best
Practices: Designing Touch Tablet Experiences for Preschoolers. nes de la pantalla, crear acciones cuando los niños mueven el disposi- 
tivo, lo que permite una interacción más "real." Podría ser interesante generar propuestas de juego que respondan al movimiento del dispositivo (tilt \& shake), lo que representa actualmente en el mercado un minoría de aplicaciones. No obstante debido al peso de las tabletas esta funcionalidad es difícil para ser controlada por los niños en dicho dispositivo. Para dispositivos como pueden ser los teléfonos inteligentes, esta funcionalidad es más manejable. Por lo que se recomendaría su aplicación principalmente para dispositivos pequeños ${ }^{5}$.

\subsubsection{Acciones a evitar}

Deslizar les resulta complicado. Si el juego requiere del uso de un botón que se ha de deslizar de un lado a otro, por ejemplo para limpiar la pantalla tras realizar garabatos, sería recomendable que existieran

fuertes indicaciones visuales que marcaran explícitamente el recorrido y el punto final. Solamente los niños más mayores (dentro del rango de estudio) podrán realizar dicha acción.

Algunas acciones comunes en algunos tipos de Apps que también resultan demasiado difíciles para los niños menores de dos años y se deberían evitar son el pinch o pellizcar para cambiar por ejemplo el tamaño de objetos, el flick o fling que se basa en pinchar en el objeto para lanzarlo virtualmente con el movimiento del dedo y el double tap/doble golpe ya que los niños esperan un feedback inmediato por lo que no van a entender que se requiera un segundo toque.

3.3. Tipologías de Apps y características interactivas recomendadas En el proceso de diseño de Apps se deben explotar las propiedades interactivas que los diferencian de otros soportes, evitando crear traducciones directas de las propuestas tradicionales llevadas al plano digital. Por ello, se han investigado las propuestas interactivas que aprovecharían las características que brindan los dispositivos móviles para generar Apps diferenciales aptas para su uso con bebés.

3.3.1. Apps Reactivas, Manipulativas o Constructivas

Las investigadoras australianas Kate Highfield y Kristy Kate Goodwin de la Universidad de Macquarie, han propuesto un sistema de evaluación de aplicaciones educativas para aprender matemáticas que las divide en tres categorías: instructivas, manipulativas o constructivas $^{6}$. Siguiendo su enfoque generamos una clasificación ligeramente diferente para nuestra investigación, clasificando las aplicaciones en reactivas, manipulativas o instructivas.

El diseño de apps reactivas permite a los usuarios interactuar libre5 SesameWorkshop (2012) Best Practices: Designing Touch Tablet 6 HIGHFIELD, K: GOODWIN, K. (2013) Apps for Mathematics Learning: A Review of "Educational" Apps from the iTunes App Store. 6th annual conference of the Mathematics Education Research Group of Australasia y la madurez del niño. Son juegos que requieren acciones aleatorias simples (pulsar en cualquier lugar en la pantalla, mover el dispositivo azar) para obtener diferentes reacciones (algo que aparece en la pantalla, cambio de colores, formas, música, sonidos, etc). Las apps manipulativas son las que permiten manipular elementos, facilitando un descubrimiento guiado y una experimentación en un contexto predeterminado. Las apps instructivas tienen elementos de ejercicio y práctica. Contienen tareas predeterminadas en las que se requiere una respuesta homogénea por parte del usuario.

La tipología de interacción que sería más adecuada para toda la etapa de cero a dos años sería la reactiva. Poco a poco, cerca del año se podría presentar al pequeño alguna App de propiedades manipulativas, aunque el bebé no podrá realmente controlar bien hasta que pasen unos meses. El pequeño podrá empezar a interactuar con Apps instructivas cerca de dos años, pero de nuevo le costará realizar las acciones requeridas y necesitará de práctica durante un tiempo.

\subsubsection{Apps personalizables}

Una característica relevante a la hora de generar Apps para niños pequeños es que permitan en un amplio sentido de la palabra, personalizar el juego. No todos los niños son iguales ni tienen las mismas capacidades ni intereses. Un potencial positivo de los juegos para dispositivos móviles es que pueden presentar opciones de diferenciación que permitan la individualización del juego ${ }^{7}$.

Personalizar el contenido con información del entorno real:

- Fotos y vídeos: permitir la incorporación de fotografías de familiares y conocidos, objetos, sonidos de su entorno real para que formen parte del juego. $U$ ofertar una amplia gama de variantes de imágenes para facilitar la elección de opciones similares a la realidad del niño. Existen otras opciones creativas de registrar el entorno en la pantalla como por ejemplo que la App detecte la forma del objeto colocado encima de la pantalla para que ésta sea añadida a la propuesta lúdica.

- Palabras y frases cortas que el niño escucha en su día a día reforzando así con la repetición a través del mundo físico y digital el aprendizaje. Por ejemplo nombre y datos específicos del niño. Con mensajes específicos según el momento del día: vamos a dormir, a comer! O respuestas personalizadas según qué preguntas se formulen. Por ejemplo los padres de un niño al que llaman "principito" de forma cariñosa en casa preguntan: "Vamos a dormir?" y la App contesta "Si!!! Buenas noches Principito".
7 SHULER, C. (2009) Pockets of potential. Using mobile technologies to promote children's learning The Joan Ganz Cooney Center at Sesame Workshop. 8 HISH-PASEK, K. (2013) Too Young for children? The Kristin Anderson Organization Moore Lecture Series. Child Trends

Los niños aprenden mejor cuando una persona interactúa con ellos directamente 8 . Al personalizar las aplicaciones se permite al niño y al adulto jugar digitalmente aprendiendo sobre las cosas que experimentan en su entorno real cercano. Las Apps se han de desarrollar con la idea de crear herramientas que faciliten al adulto hablar y repetir palabras sobre lo que v ven en su día a día. Si un niño puede alinear su aprendizaje con situaciones reales, escenarios y entornos cercanos, puede recordar conceptos básicos y vocabulario más fácilmente ${ }^{9}$. 
Personalizar el contenido combinando digital con real:

- Incorporar información del entorno real en el juego digital. Los sistemas de posicionamiento global (GPS) en los dispositivos móviles permiten mejorar una nueva forma de interacción con el entorno, combinando la información virtual con las experiencias en el mundo real?

- Incorporar en el juego, objetos que el pequeño tiene a su alrededor. Existen tecnologías que permiten que la interacción con cualquier objeto pueda ser reflejada en la pantalla con algún tipo de acción. Por ejemplo al mover su peluche preferido se genera una imagen del recorrido o un sonido según la intensidad y el tipo de movimiento.

3.3.3. Apps que fomenten la interacción social

Las aplicaciones y los dispositivos móviles deberían pensarse para que proporcionen a los padres nuevas herramientas que generen propuestas para experimentar desarrollando diversas interacciones verbales y gestuales con sus hijos ${ }^{10}$, como por ejemplo proponerles temas de conversación o presentarles ideas para generar juegos de gestos, de tocarse, abrazarse, etc. Muchos padres no tienen formación en temas lúdicos o educativos y muchas veces sienten que les faltan conocimientos sobre actividades para hacer con sus bebés.

Según el psicólogo Mateo Killingsworth especialista en formas de crianza de las familias actuales, vivimos en una realidad en la que los padres priorizan pasar su tiempo con otras personas antes que con sus hijos ${ }^{11}$. Esto muestra la necesidad de crear propuestas que ayuden a los padres a divertirse junto con sus pequeños. Y para ello es muy importante diseñar teniendo en cuenta a los padres, generando apps que también aludan a sus intereses, para que jueguen con gusto con sus pequeños. Rosemarie t. Truglio, vice presidenta de educación e investigación de sesame workshop indica que no desarrollan contenidos solo para el niño, los especialistas en barrio sesamo crean contenidos que incluyen en la experiencia a los padres. Diseñan por tanto en dos niveles para conseguir la co-participación de niños y adultos.

Por otro lado, es relevante construir actividades que requieran una participación activa no pasiva por parte del infante ${ }^{12}$. La participación

sobre todo antes del año, se traduce en permitir al niño realizar acciones por azar que generen una respuesta en el dispositivo.

3.3.3. Apps que fomenten la interacción con el entorno y con objetos físicos

Otra característica ya anteriormente debatida es la importancia de presentar opciones que permitan el juego digital combinado con el juego físico. Es fundamental proporcionar un ambiente rico en experiencias sensoriales que permitan la exploración con objetos físicos. Los juegos digitales tienen muchas restricciones en éste aspecto, especialmente en edades tan tempranas. Es adecuado generar propuestas de juegos en los que se combine el juego de Apps que requieran de la interacción con juguetes específicos u objetos del entorno real del niño.

\section{Consideraciones estéticas y de formato}

\subsection{Colores e imágenes}

Durante los tres primeros meses de edad se puede ejercitar la visión del bebé mostrándole objetos con contrastes fuertes: blancos y negros, blancos y rojos, blancos o amarillos pálidos con rojo intenso, etc. Al bebé le llamarán la atención sobre todo estos estímulos contrastados, prestándoles más atención. A partir del cuarto mes ya pueden distinguir entre distintas tonalidades de rojos y amarillos. Los colores pasteles no les llaman la atención ${ }^{13}$.

En esta fase son estímulos visuales adecuados para los bebés mágenes lineales simples como cuadrados, círculos y triángulos, ojos de buey o espirales (más hacia los 3 meses), un tablero de ajedrez o rayas paralelas anchas, todo de un color sobre un fondo de color muy diferente y contrastado. Teniendo en cuenta que prefieren el rostro humano a cualquier otra imagen, también es una buena opción mostrar imágenes de caras muy esquemáticas en los primeros meses, para pasar a mostrar caras de personas, sobretodo familiares ${ }^{14}$

Al principio los movimientos que el bebé seguirá con más facilidad serán los horizontales, después los verticales y finalmente podrá prestar atención a los movimientos circulares. Durante el primer mes de vida, el bebé ya empieza a seguir con la vista el recorrido de objetos con movimiento, por lo tanto, para potenciar el desarrollo de esta habilidad, se pueden proponer juegos de seguimiento ocular. Se le puede mostrar un objeto o imagen moviéndose de arriba abajo o de un lado a otro, sabiendo que al principio sólo podrá seguir objetos grandes moviéndose despacio y durante una trayectoria corta para poco a poco ir siguiendo mejor objetos pequeños que se muevan más deprisa.

Si hay que elegir un color que llame más la atención de los pequeños es el rojo, no se sabe bien porqué pero los recién nacidos fijan más la mirada en ese color. A partir del cuarto mes también muestran preferencia por el azul.

Según la guía para padres de Juegos y juguetes que publica anualmente AIJU (Instituto Tecnológico de Productos Infantiles y Ocio), exis-
13 SEARS, W. (2013). The baby book. Little, Brown and Company first year. American Academy of Pediatrics, Ediciones Medici 15 YOST, P. (2007). Science of Babies, National Geographic 16 PULASKI, M. A. (1989) El desarrollo de la mente infantil según Piaget. Ediciones Paidós PesameWorkshop (2012) Best Experiences for Preschoolers ten diferentes formas de estimular la visión de bebé como por ejemplo proporcionándole imágenes (fotos de bebés o de familiares conocidos) e ilustraciones diversas, al principio, como se ha dicho, de colores muy contrastados. Se les puede mostrar objetos que estén a su vista y luego hacerle ver que siguen ahí (con lo que aprenderá la noción de "permanencia de objeto"). Además, para favorecer la acomodación visual es importante mostrarle objetos que se acercan y se alejan. También ayuda a la atención temprana ir nombrándole objetos a la vez que se le muestran, o utilizar objetos con luces suaves para despertar su curiosidad visual ${ }^{15}$. 


\section{Fuentes}

COSTA, M; BUSÓ, P.; MORANTE, M.; BLANCO, P. (2014) Tendencias en Puericultura 2014-2015. Pe GEE, J.P. (2008) Getting over the slump: Innovation strategies to pro mote children's learning. The Joan Ganz Cooney Center at Sesame Workshop. GOODWIN, K.; HIGHFIELD, K. (2012). iTeach and iLearn-An examination of "educational" apps. Early Education and Tech Children Conference. How electronic media -from baby videos to educational softwarevideos to educational softwareBooks. GUERNSEY, L. (2013) Too Young for children? The Kristin Anderson Moore Lecture Series. Child Trends Organization.

HIGHFIELD, K.; GOODWIN, K.

Learning: A Review of "Educational" Apps from the iTunes App Store. 6th annual conference of the Mathematics Education Research. Group of Australasia

HISH-PASEK, K. (2013) Too Young for children? The Kristin Anderson Moore Lecture Series. Child Trends Organization.

PULASKI, M. A. (1989) El desarrollo de la mente infantil según Piaget. Ediciones Paidós

Childen's. (2013). Zero to Eight: Common Sense Media. SEARS, W. (2013). The baby book. Little, Brown and Company SENIOR, J. (2014) All joy no fun. The paradox of modern parenthood. Harper Collins Publishers. SESAMEWORKSHOP (2012) Best Practices: Designing Touch Tablet Experiences for Preschoolers first year. American Academy of Pediatrics, Ediciones Medici SHULER, C. (2009) Pockets of potential. Using mobile technologies to promote children's learning The Joan Ganz Cooney Center at Sesame Workshop YOST, P. (2007). Science of Babies, National Geographic
Ya a los cuatro o cinco meses los bebés observan figuras de objetos familiares mientras se los nombra; pelota, camión, etc ${ }^{16}$. Se puede así empezar a estimular el lenguaje mediante Apps que tengan imágenes de dibujos sencillos o fotografías. Una opción sería que en la App se pudieran añadir imágenes de objetos y juguetes que el niño tiene a su alrededor, es decir que el adulto realizara fotografías por ejemplo de a familia, de su propio coche, etc., y estas pudieran insertarse en la aplicación.

Se ha de tener en consideración que en un primer lugar los pequeños entenderán mejor las fotografías, a continuación las imágenes ilustradas con carácter realista y poco a poco las ilustraciones más abstractas. Aún así se puede mostrar ilustraciones desde el nacimiento, ya que son interesantes desde el punto de vista de aportar estímulos visuales que favorezcan la apreciación de diversas estéticas.

Otra propiedad de las imágenes que ha considerarse es que hay que tener cuidado con los flashes que pueden deslumbrar y afectar al bebé por su menor capacidad de adaptación de la pupila. Una de las Apps más usadas por los padres con bebés entrevistados, My baby Firework, genera unos destellos muy impactantes, que pueden no ser adecuados para los ojos de los pequeños.

\subsection{Disposición de elementos en la pantalla: botones e iconos}

Al resaltar elementos interactivos, como botones e iconos se facilita al niño dirigir su atención. Este recurso es relevante con niños más mayores, pero durante los primeros meses se debería evitar colocar en la pantalla botones con funciones específicas más allá de las necesarias para el juego en esa pantalla. Los pequeños no tienen control sobre dónde tocan, si aprietan un botón será por azar y este les llevará a un resultado diferente al esperado. En esta etapa si el juego contiene botones con funciones como el Home, hay que intentar que no resalten visualmente para que no atraigan al niño, que suele darle constantemente.

Sin embargo, cerca del año de vida, les encanta apretar botones por lo que son interesantes los juegos cuyo objetivo es precisamente dar a botones (al azar por el placer de generar reacciones sonoras o visuales), pero aún sin funciones específicas.

Cerca del año y medio empiezan a entender mejor que cada botón responde a una función específica por lo que se podría comenzar a distinguir visualmente elementos como botones (usando para estos elementos diferente color, contraste, grosor de línea o estética que la del resto de la imagen que aparece en pantalla) ${ }^{17}$.

Para llamar la atención y explicar visualmente qué elementos son interactivos, estos se deberían resaltar. Podrían usarse recursos que los hagan destacar, como rodearlos de un borde de color contrastado. Por el contrario, los objetos que no son interactivos no deberían parecerlo. Y si existiera un botón sólo para padres no debería llamar la atención de los niños.

Los pequeños tienden a coger el dispositivo de forma que sus dedos tocan parte de la pantalla o incluso en algunas posiciones descan- $\overline{\text { Miriam Morante }}$

Especialista en el mundo de diseño para niños como diseñador investigadora y profesora. Cuenta con experiencia en varias empres trabaiado más de siete años Instituto Tecnológico de Producto Infantil y Ocio. Ha coordinado diversos proyectos como el Obser vatorio de Tendencias Infantiles y Concurso Internacional de Diseño de Juguetes. Además de gestion y colaborar en la formación de diseñadores a través de diplomas
masters especializados.

Nuria Rodríguez

Artista y docente. Profesora Titular en la Universidad Politécnica de Valencia. Directora de Unit experimental, grupo investigador multidiscipliar especializado en Reaidad aumentada aplicada a eventos culturales. Doctora en Bellas Artes $y$ titulada en Diseño Industrial por a Escuela Superior de Diseño de Valencia. Directora del Master en Piseno e llustración (UPV). Como práctica de la pintura ha realiza varias exposiciones individuales como Historia natural Itomo XXIII en 2015, El desorden de las cosas en 2014 y Álbum, atlas, cuadernos de notas en 2010.

$\overline{\text { María Costa }}$

Doctora en Filosofía y Ciencias de a Educación por la Universidad de mento de consumo infantil y ocio de AlJU desde 1992. Tiene una arga carrera profesional en diversas áreas de especialización: niños e infancia, diseño para todos, consumidores, productos educativos, juegos, nuevas tecnologías, etc. Ha coordinado y gestionado proyectos científico-técnicos tanto regiona es, nacionales como europeos. y es consultora de empresas de industriales y otras organizaciones a nivel nacional e internacional. san sus muñecas en los bordes inferiores de ésta. Ello imposibilita a veces el juego y crea "accidentes" si los botones y elementos a tocar están en esas zonas. Por ello, es mejor colocar los elementos, botones o iconos en la parte de arriba de la pantalla.

\section{Orientación de la App}

Durante los primeros meses el niño no es quien coge el dispositivo, los adultos o niños mayores que interactuan con él son los que le colocan correctamente la orientación de la App. Por lo tanto, no tiene mucha relevancia la orientación (vertical u horizontal) del juego.

Cuando el niño empieza la interacción manipulativa y táctil, la App debería ser igual indistintamente de la orientación en la que se coja el dispositivo. Por ello, las propuestas de juego más adecuadas son las que no presentan orientación específica. Un buen ejemplo de App en estas líneas es Touch the Ladybug, juego en el que una mariquita se va moviendo por la pantalla en cualquier dirección y el niño ha de tocarla para que sus alas se abran.

Los niños de alrededor de año y medio cogen cada dispositivo en la posición más común. Por lo tanto, para desarrollar Apps para bebés es importante que se puedan jugar con la tableta de forma horizontal y el móvil en vertical. No obstante, el pequeño irá poco a poco entendiendo la orientación de las imágenes especialmente si se le muestran imágenes conocidas: caras, animales/mascotas, etc., y podrá cambiar a la orientación correcta, sobretodo cerca de los dos años de vida.

\section{Conclusiones}

Cada vez existen más aplicaciones para bebés accesibles en el mercado. Y los padres están usándolas con sus pequeños. Pero los bebés son muy vulnerables en esta etapa de su vida a los impactos y experiencias que les rodean. Por ello, cobra gran importancia diseñar bien las aplicaciones que van a ser utilizadas por bebés, para no causar daños o efectos nocivos y aprovechar sus posibles efectos positivos.

Otros productos infantiles, como los juguetes, han acompañado a la humanidad durante toda su historia. Estos objetos han sido han sido ampliamente estudiados y existe multitud de documentación para que los diseñadores y creadores de estos productos puedan desarrollarlos de la forma más adecuada posible.

Ante la falta de documentación específica, la presente investigación facilita una serie de recomendaciones que sirven de apoyo para mejorar el desarrollo de Apps para bebés. Con nuestra aportación ampliamos e conocimiento científico sobre la materia, aportando datos relevantes no sólo para diseñadores sino en general para la industria, así como para centros de formación y universidades. 